\title{
Teacher Capacity for Curriculum Differentiation in Teaching Foundation Phase Mathematics
}

\author{
M.A. Marishane ${ }^{1}$, R.N. Marishane ${ }^{2}$ and F.D. Mahlo $^{3}$ \\ ${ }^{1}$ Limpopo Department of Education, South Africa \\ ${ }^{2}$ University of Pretoria, South Africa \\ ${ }^{3}$ University of South Africa, South Africa

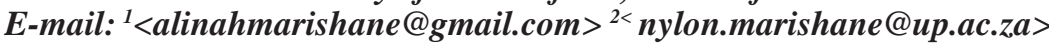 \\ ${ }^{3}<$ mahlofd@unisa.ac.za $>$
}

KEYWORDS Anchoring. Compacting. Grouping. Instruction. Modification

ABSTRACT The teaching of mathematics in South African schools is placed among the worst in the world, despite recognizing the development of the country as a knowledge economy that largely depends on mathematics teaching and competency. The simple logic flowing from this line of thinking is that for learners to perform in mathematics, they need competent teachers who are responsive to the context of the right to basic education. Inclusive education defines such context. For effective teaching of mathematics within an inclusive education setting to be possible in lower grades, this study argues for differentiated teaching practices to support all learners. For this to be possible, teachers need capacity to carry out curriculum differentiation. This study followed a qualitative approach in which data was collected through observations, document analysis and interviews. The results show that Foundation Phase Mathematics teachers face such challenges as the lack of training in curriculum differentiation and the inability to respond to learner diversity.

\section{INTRODUCTION}

South Africa is following a policy of inclusive education. Global organizations such as the World Bank, United Nations Educational, Scientific and Cultural Organization and Organization for Economic Cooperation and Development support the policy. Inclusive education is both a process and an approach to education. As a process, it involves modification of content, structures, approaches and strategies to cover all children (UNESCO 2009). As an approach, inclusive education aims at realizing a broader vision of the World Declaration on Education for All (UNESCO 2000). One fundamental principle underpinning this approach is that all learners, despite their differences in age, ethnicity, language, class, disability and HIV status, should learn together (INEE 2009:7). What is important, in this case, is to strengthen learner participation in the learning processes, activities and environment by identifying and removing barriers to learning, especially where such learning includes all learners. The curriculum is identified as one of the major barriers to developing inclusive education (UNESCO 2003:16). There are several curriculum-based factors limiting learners' access to inclusive education. They range from content, assessment, teaching styles, learning sup- port materials and equipment, instructional time, methods and processes to medium of instruction, classroom organization and management (Department of Education 2001:19). Since teachers are recognized as important agents in curriculum implementation (Mokua 2010), their knowledge of and skills in these issues is of paramount importance. What this suggests is that teachers hold a key to opening the doors of learning, ensuring access of all learners to education through the curriculum.

\section{How Teachers Help All Learners Access Curriculum}

Accessing the curriculum is part of children's fundamental right to basic education and teachers are duty-bound to guarantee this right. They have a social and professional responsibility to accomplish this (UNESCO 2004). One important way of guaranteeing children's right to education is for teachers as duty bearers to ensure that curriculum is not only accessible, but also inclusive for all learners. For them to succeed in achieving this, differentiation of curriculum is critical. Curriculum differentiation is a strategy that involves modification, adaptation and extension of methodologies, instructional and assessment strategies and curriculum con- 
tent, placing special emphasis on learners’ abilities, interests and backgrounds (Department of Basic Education 2011a:4). In practice, it involves differentiating instruction by "identifying students' individual learning strengths, needs, and interests and adapting lessons to match them" (Sparks 2015: Para. 2). Such differentiation is based on the application of several basic principles that form the teacher's repertoire of knowledge and skills needed when teaching learners in an inclusive classroom setting. Among the most prominent of these principles are the following (Tomlinson and Strickland 2005):

Establishing flexible grouping (creating opportunities for individual learners to contribute to others' learning in groups of their choice and benefit from them)

Presenting a high quality curriculum (ensuring that curriculum is coherent, exciting, invitational and thought-provoking to learners)

Engaging learners in respectable learning tasks (giving learners tasks, which are appealing and meaningful, providing them with requisite skills, knowledge and understanding)

Assessing learners continuously (applying a continuous mix of formal and informal assessment of learners and using the results of such assessment to adjust instruction to learners' abilities)

Considering the above-mentioned principles, it follows that for curriculum to be accessible to learners, it should provide space for accommodating all their individual differences and needs. To realize this, learners need best learning support from teachers as actors who are in direct contact with curriculum and are thus, well positioned to differentiate it and ensure access to it. For teachers to succeed in supporting all learners to reach their potential, they need to be capable for the task, that is, they need capacity. Building capacity for teachers involves providing them with necessary materials and 'tools' they need for effective teaching (Egbo 2011). This includes equipping teachers with the knowledge of curriculum differentiation and skills for planning lessons and organizing classroom activities guided by such knowledge. Many teachers, however, lack knowledge and skills needed to adapt curriculum to the individual needs of learners (UNESCO 2005; Vaillant 2011). The spotlight now shifts to teachers' capacity to differentiate curriculum.

\section{Teacher Capacity as a Critical Element of Differentiated Mathematics Instruction}

There are two key factors contributing to poor learner achievement in mathematics in South African schools, namely, poor subject knowledge and poor teaching competencies on the part of teachers (Taylor 2011). This suggests that the learners' performance in mathematics requires teachers who know what to teach (Mathematics content), how to teach (differentiating Mathematics instruction), and how children learn (modalities of learning Mathematics) within a defined context (inclusive education setting). This reinforces the critical importance of teaching and learning in an inclusive environment, shaped by such elements as differentiated classroom, instructional process, content and learning products (Corley 2005; Tomlinson and Strickland 2005; Watts 2010). Considered collectively, these elements show that if teachers are not grounded in Mathematics content and the pedagogy of teaching it in a differentiated way, then learners' academic achievement in the subject is unlikely to improve. As Nel (2007:2) points out, teachers need to be qualified and demonstrate competence, dedication and care in order to meet the needs of each learner and ensure their success. The implication of this view for Mathematics teachers is that learners should be taught Mathematics differently. Differentiated instruction involves teaching learners in such a way that they do not only master essential content and skills, but also assume ownership thereof (Tomlinson 2008). This necessitates bridging the gap between Mathematics and learners by teaching according to the differentiated needs of learners.

To close the learner-subject gap, teachers need capacity in the form of professional development. This is a kind of development that equips teachers with knowledge, skills, values and attitudes needed for effective education of learners (Steyn 2004). For professional development to be effective, it should focus on content and teaching strategies to communicate that content to learners (Archibald et al. 2011). Literature presents various professional development models for teachers, ranging from traditional models such as workshops and seminars (Borko 2004) to job-embedded professional development practices such as teacher networks, peer observation practices and school-based coach- 
ing (Darling-Hammond et al. 2009). While the former models are criticized for lack effectiveness, specificity and sustainability and for their emphasis on professional development rather than professional learning (Fullan 2007; Easton 2008), the latter models are commended for benefiting both teachers and their learners (AERA 2005:2-3). It is important to note that the criticism leveled against traditional development models and support for job-embedded models align with what other studies have found, namely, that differentiated instruction requires continuous and consistent professional development wherein patience, time and energy matter the most (Blozowich 2001; Pierce and Adams). This is fundamentally important for professional development of Mathematics teachers.

\section{Why Curriculum Differentiation Matters for the Teaching of Mathematics in South African Schools}

To understand the importance of curriculum differentiation in the teaching of Mathematics, one has to understand the context in which the curriculum is delivered and teacher responsiveness to that context. Curriculum in general and in Mathematics teaching in particular is delivered within the context of inclusive education. Inclusive education recognizes and respects individual differences existing in learners, thus strengthening the empirically tested belief that "no two children are the same" (UNESCO 2001: 7). In South Africa, inclusive education is factored in the Curriculum and Assessment Policy Statement (CAPS) for Mathematics, packaged with guidelines for teaching and assessing learners according to their diversity (Department of Education 2011b). How teachers teach Mathematics to respond to the demands of an inclusive education context is, however, discomforting. Data from studies conducted in recent years reveals that learners in South African schools are performing poorly in Mathematics, particularly in comparison to learners in other countries (Spaull 2013; Siyepu 2013). This continues despite the strong belief in the contribution of numeracy and Mathematics teaching to the development of the country as a knowledge economy (McCarthy and Oliphant 2013).

Reports from studies conducted in recent years show that curriculum differentiation in teaching subjects like Mathematics benefits both gifted learners and low-attaining learners. Three examples can be cited in this regard. Firstly, a study into effective teaching and learning for pupils in low-attaining groups (Dunne et al. 2007) has found that when curriculum differentiation is followed in such extra support programs as literacy/English and numeracy/Mathematics, low-attaining learners no longer show signs of withdrawal from their class. What this implies is that curriculum differentiation enhances the learners' sense of self-confidence as they use their strengths to overcome their weaknesses. Secondly, a study into curriculum differentiation for gifted primary school Mathematics learners (Wilkins et al. 2006) shows that differentiated curriculum enables gifted learners to reach their potential in Mathematics by developing their skills, motivation and perseverance. In other words, these learners learn not to take things for granted, but rather to see Mathematics as a subject in which they have to put an effort to achieve success. Lastly, the study conducted in the US (Mastropieri et al. 2006) shows that differentiated curriculum enhancement improves the academic benefit of these learners by eliminating any feeling of isolation from the teaching and learning process.

\section{Strategies Applied in Differentiated Mathematics Instruction}

Mathematics, like any other subject taught in an inclusive educational setting, requires subject-specific differentiation strategies, which will guarantee learner's access to curriculum. Guided by principles underpinning differentiation and depending on learners' readiness, interests and learning styles, the following examples of strategies are applied in differentiating instruction in Mathematics (Kingore 2007; Pierce and Adams 2004):

Compacting: Adjusting instruction in response to the learner's mastering of learning objectives.

Presenting tiered lessons: Predetermining learning objectives for a lesson and assigning tasks of varying complexity and abstractness to learners.

Anchoring: Giving learners work to do while awaiting further instruction from the teacher to proceed with other activities

It is important for a teacher to understand that the differentiation strategies presented here 
are not the end, but the means towards improved learning. Their application during lessons will ensure that the different needs of all learners in the classroom are catered for, enabling them to gain access to Mathematics.

\section{Aim and Objectives of the Study}

The aim of this paper was to examine capacity building needed for Foundation Phase Mathematics teachers with focus on curriculum differentiation. The objectives of the study emerging from the research aim were to examine how teachers respond to learner diversity in the class and to identify challenges they experience when applying curriculum differentiation in the class.

\section{METHODOLOGY}

The study was qualitative in nature and applied three data collection strategies, namely, analysis of documents, observations and interviews. The application of multiple strategies here was meant to maximize the credibility and trustworthiness of the study through triangulation, which is, using various methods in the study of one object (Devetak et al. 2010:79). Documents, which researchers studied with permission from four teachers whose lessons were observed, included teachers' workbooks and curriculum policy documents. The purpose of studying these documents was to establish the extent to which the planning of lessons aligned with the policy documents and the actual teaching of Mathematics in the Foundation Phase. To understand classroom practices and interactions as research suggests (Flick 2009), the researchers found it imperative to collect data by observing teacherlearner interaction during the Mathematics lessons in the classroom. For data capturing, the researchers used a pre-designed observation protocol containing key principles guiding differentiated instruction. For collection of interview data in this study, three focus group interviews with Foundation Phase Mathematics teachers and one in-depth interview with a curriculum advisor for Mathematics (serving also as a professional development facilitator) were conducted and data was tape-recorded for subsequent data transcription and analysis. In both cases, informed consent forms were issued and completed after the Limpopo Department of Education granted permission for the study.
Each focus group interview comprised five teachers selected in a purposive sample of three schools drawn from a population of twenty-three schools in one circuit in Limpopo Province. The criteria used in the selection of participating teachers were that (a) teachers involved should have attended at least one workshop on curriculum organized by the Circuit, and (b) worked for more than one year as subject teacher in the Foundation Phase. To ensure anonymity of participants, schools were designated as School A, School B and School C. For data collection an interview guide was used to cover questions grouped into three major themes, namely, (a) teachers' response to learner diversity, (b) challenges relating to capacity building for Mathematics teachers, and (c) district-initiated capacity-building programs for Mathematics teachers. The first theme covered two sub-themes, namely, learner participation in the lesson and assessment strategies teachers applied. The second theme covered challenges relating to continuing professional development and monitoring and support. The third theme covered issues such as training modalities, teacher participation during training and alignment of training with CAPS.

\section{RESULTS}

For the purpose of answering the three research questions and meet the objectives of the study, data from documents, observations and interviews was analyzed according to themes and sub-themes as presented below. The following are the results of the study presented here in the form of the three themes that covered the interview sessions.

\section{Teachers' Responses to Learner Diversity}

\section{Learner Participation in the Lesson}

The focus here was to establish the teachers' understanding of learner diversity and the concomitant application of different teaching strategies. It was found that although teachers were aware of existing differences in learners' abilities, they appeared to be unable to apply such understanding to enhance meaningful participation of all learners in the Mathematics lessons. For instance, teachers focused more on slow learners than average and gifted ones, vir- 
tually limiting the right of access of the latter to curriculum. They held the view that the gifted and the average learners understood the learning content and that there was no need to focus on their participation in the lesson other than keeping them busy. By keeping these learners busy, teachers appeared to lack knowledge of key principles guiding differentiated instruction advocated in literature such as, for example, giving learners 'respectable tasks' (Tomlinson and Strickland 2005). A teacher at School A raised this point by admitting that: If you are teaching, helping those weak ones, you must give the intelligent ones enough work to let them not to play when you are helping those ones. In addition, consideration was rarely given to the application of different teaching strategies to cater for learners with different mathematical abilities. Whenever this was considered, learners were either grouped according to their abilities (School A) or when there was a need (Schools B). The teacher at School C argued: I don't group my learners, because I can see it encourages copying. This reinforced what the researchers observed during lessons, notably, that some Mathematics teachers in the schools they visited were not aware of the importance of flexible grouping. While these teachers organized learners into smaller manageable groups during lessons, they discouraged them from joining groups of their own choice. Grade R learners at School A were instructed to sit still, keep quiet and listen attentively to the teacher or they would be chased out of the classroom. Learners in a Grade 3 class at School $\mathbf{C}$ were grouped according to their abilities and instructed to stick to their allocated groups, irrespective of whether those learners were comfortable to work with members of those groups.

\section{Learning Support Materials}

All the classrooms the researchers visited had the essential physical resources such as physical objects of various color and shapes, including counters, charts and number lines and grids. Though learners in some were aware of these learning support materials and were effectively used as at School B, where the teachers used themselves as demonstration tools before referring learners to concrete objects, learners in other schools such as School A and C were not made aware of the significance of these resources.

\section{Respectable Tasks}

The study found that although the CAPS policy document for the Foundation Phase Mathematics (South Africa 2011b) makes provision for teachers to give learners meaningful tasks, some teachers relied heavily on the examples of tasks provided in the policy document. What was comforting, however, during the researchers' observation of two separate lessons at School B, was to discover that some Mathematics teachers were innovative and created their own tasks in order to captivate the learners' interest in the lessons.

\section{Applied Assessment Strategies}

The focus here was to examine strategies the Mathematics teachers were applying to assess their learners. While teachers at the three schools assessed their learners continuously, they appeared to rely mainly on written work as a preferred assessment strategy. For example, during their observation of lessons, the researchers found that the preferred modes of assessment were oral questioning and written work in the form of written class work exercises and formal assessment tasks such as monthly tests with insufficient attention given to observation. This contrasted with what literature on differentiation advocates, namely, the use of various assessment strategies (Poham 2008). Teaches interviewed indicated that they seldom used observation as one of the assessment strategies, because they regarded it as time-consuming and whenever they used the strategy they would record their learners' performance after the lesson. A teacher from School A explained:

I think during the lesson you can't teach them and write at the same time. You must just know that this one is doing this and after a lesson you must sit down and take the record sheet and record that.

Teachers at School C assessed learners through written work, because they did not know other assessment strategies. At School B teachers indicated that at times they assessed learners orally, but they did not record such assessment. The study of teachers' workbooks confirmed what the teachers said. For instance, with the exception of School A, the study of teachers' workbooks showed that teachers' lesson plans did not make any provision for assessment, resources and teacher reflections. It emerged that some teachers were not aware that 
learners should be assessed informally and formally, using a variety of strategies such as observation, written work and performance-based demonstration outlined in the CAPS document.

\section{Differentiating Content and Questioning Strategies}

It emerged during all the lessons observed, that many teachers gave insufficient consideration to differentiating content and attending to individual learners' preferred mode of responding to questions. With the exception of one teacher at School B, all teachers did not differentiate content by applying instructional strategies that would ensure that content was adapted to the different learning styles of learners as suggested in literature (Kingore 2007; Pierce and Adams 2004). During a Grade 3 lesson on numbers, operations and relationships at School C, learners who skipped one or two numbers when counting orally, were passed over for those who could count properly. The teacher took no effort to ask learners to write down the numbers they could not count orally. This contrasted with the application of appropriate questioning strategies research advocates (UNESCO 2004).

\section{Capacity Building Challenges for Mathematics Teachers}

\section{Continuing Professional Development for Mathematics Teachers}

Teachers' challenges towards capacity building revolved around the type, length and scope covered by training they received from the Limpopo Department of Education. According to the participants, teachers for each grade in the Foundation Phase attended a three-day onceoff workshop organized and facilitated by curriculum advisers for Mathematics teachers in the Circuit and held at a central place. The workshop focused more on the Mathematics curriculum content and fewer on strategies for assessing and teaching Mathematics lessons. A typical workshop for Grade R teachers would start on a Friday midday and end on a Sunday midday in a central venue outside their circuit.

\section{Attitudes Towards Workshops}

All the participants expressed a sense of disaffection with the training they received from the presenters during workshops. Such disaf- fection ranged from the timing for the workshops and the facilitation strategies applied by the curriculum advisors to the content covered during the workshops. One Grade 2 teacher from School A expressed a personal experience in the following words:

My view is that the time is three days and it is so very short. They pile us with a lot of work and they don't really explain what is to be done. They just give us the sheet to write our points and then they come and collect the sheets from us, read sheet by sheet and try to collect the points and then they just summarize. Sometimes you go there and come back not really having understood what should be done. After collecting those points they give us work to do.

A Grade 3 teacher from School B had this to say about curriculum advisors:

Sometimes they start a lesson on Friday at ten o'clock and then after five o'clock they give us work - more work to do to prepare for the next day and sometimes we don't understand what their roles are. Instead, they tell us something they don't understand themselves. They are collecting some ideas from us.

It emerged from the interviews that teachers were not satisfied with the content delivered at the workshops. One Grade 1 teacher from School C said: I went for training for two days where the presenters gave us just a list of topics that we must deal with in the classroom. They did not teach us anything; we were still waiting for the whole content of Mathematics to understand this CAPS.

\section{Monitoring and Support}

The Mathematics teachers interviewed complained about the subject advisors who facilitated training and never conducted follow-up school support and monitoring visits. One teacher at School B wondered: "How can they monitor us when they don't do the spade work?" With views like this, the researchers noted that teachers' attitude towards the once-off workshop as a continuing professional development modality and lack of subsequent follow-up school visits teachers' challenges. For instance, literature shows that workshops are effective only when they are followed by job-embedded professional activities (Tate 2009). This emphasizes the importance of coupling workshops with school-based support programs. 


\section{District-initiated Capacity Building Strategy for Mathematics Teachers}

The interview held with the Curriculum Advisor for Mathematics covered issues relating to training modalities, training content, teacher participation during training, alignment of training with CAPS and monitoring and support. The aim was to examine the capacity building strategies the Limpopo Department of Education applied to support Mathematics teachers. One of the key issues covered during the interview with the Curriculum Advisor related to how the training offered to the Mathematics teachers was structured. According to the Curriculum Advisor, a once-off workshop was the most common training modality followed in the district. Since the Department did not allow training of teachers in the morning, workshops took place in the afternoon at 1 o'clock. A central place that has a hall and facilities to accommodate teachers is selected to offer training in clusters rather than per circuit. The training lasted for two to three hours or two to three days, depending on the training workload.

\section{Challenges Relating to Training}

From the interview with the Curriculum Advisor, it was found that training for Mathematics teachers came with its own challenges. The challenges include lack of Mathematics content knowledge among teachers, lack of training facilities (laptops, projectors, electricity) at selected venues, long distances teachers' travel to workshop venues after school hours, teachers' negative attitudes towards Mathematics and lack of motivation on the part of curriculum advisors who have to use their own transport to workshop venues. The content covered during the training, according to the Curriculum Advisor, included the modification of the curriculum, where learning outcomes were changed to content areas such as number patterns, measurement, data handling, number operation and relationship, shape and space. Contrary to the general discontent expressed during focus group interviews by Foundation Phase Mathematics teachers about training, the Curriculum Advisor argued that teachers participated actively during training and enjoyed facilitations despite the challenges they identified. There was, however, no evidence in support of teachers' 'joy' about the training they received from their workshop facilitators.

\section{Alignment of Training with CAPS}

The focus here was to examine the extent to which training was aligned to the provision of CAPS regarding teaching and assessment in Mathematics. From the interview with the Curriculum Advisor, it was found that training of the Mathematics teachers was mainly rudimentary and focused on orientation rather than on strategies for the teaching and assessing learner in Mathematics in line with the CAPS document, which puts more emphasis on curriculum differentiation. There was no evidence of a clear strategy for aligning training with the provisions of the CAPS regarding teaching Mathematics to learners with differentiated needs. Regarding the alignment of assessment with the provisions of the policy, the only strategy the Circuit applied was that of sending model examination papers to school for teachers to use as they plan their annual national assessment (ANA) of their learners.

\section{Monitoring and Support}

The Curriculum Advisor admitted that there was no monitoring and follow-up support for Mathematics teachers and this was attributed to three factors. The first factor was the clash between the Circuit and the District programs: Sometimes when you plan, you find the District has planned something also and there is break in between. The second factor was the tight school schedule: They are also busy at schools... The last factor was lack of transport for school visits: I only sacrifice when I do workshops, but when it comes to monitoring I feel no reason why I should sacrifice also.

\section{DISCUSSION}

The results from this study point out to several important practical issues arising from the teaching of Mathematics in the Foundation Phase. The first issue relates to teachers' inability to position the teaching of Mathematics within the broader framework of inclusive education and the changes expressed in the National Curriculum and Assessment Policy Statement (CAPS) (Department of Basic Education 2011b) to advance the goals of such education. While 
the CAPS advocates differentiated instruction to ensure that the individual needs of all learners are catered for in teaching Mathematics, teachers appear not to have come to grips with how this differentiation should be carried out. In this study, for instance, the researchers found that although Mathematics teachers had the essential teaching resources (workbooks, curriculum policy documents and guides) and classrooms were well equipped with learning resources, they still needed guidance on how to plan lessons and how to communicate content to learners through the resources.

The second issue relates to a knowledge gap existing among teachers regarding how differentiation works. Their lack of understanding of differentiation strategies and principles, highly commended in literature for their success (Pierce and Adams 2004; Tomlinson and Strickland 2005; Kingore 2007), as was evident during interviews and classroom observation, is a case in point. For example, the teachers' application of classical categorization of learners into groups of 'slow learners' and groups of 'gifted learners' as a teaching strategy has already been discredited on the ground that it helps some learners while ignoring others (Ford 2005). Giving more attention to 'slow learners' than 'gifted learners', amounted to limiting the limiting the latter's right of access to curriculum.

The third issue involves creating balance between major classroom activities. While teachers in this study seemed to be aware of, albeit not fully conversant with, different learning styles, instructional and assessment strategies, they could not create a link between teaching, learning and assessment during a typical Mathematics lesson. To cite an example, though they all carried out continuous assessment, such assessment was not differentiated. They gave more attention to written assessment than other alternative assessment strategies such as oral questioning, the use of pictures, objects and visual cues suggested in literature (Quenemoen and Thurlow 2007; Poham 2008), so that all learners can benefit from the learning process. This may be attributed to insufficient continuous development for teachers as noted in the next paragraphs.

The fourth issue, which was a subject of enquiry during the interview, was that of capacity building. The interview revealed a disturbing picture of the enormous challenges teachers faced in this regard. These challenges varied from their unhappiness about modality of training and the amount and type of content covered during such training to the quality of training they received from curriculum advisors who served as trainers. Their unhappiness about training through workshops reinforces findings from literature criticizing this type of training for being insufficient in terms of effectiveness, specificity and sustainability (Fullan 2007:35). During the in-depth interview held with the Curriculum Advisor, it was noted that most of the substantial challenges that Mathematics teachers claimed to have experienced during training were well founded. What was meant to be training at the workshops was actually an information sharing session about changes brought about by the Department of Basic Education through the CAPS document. This not only cast aspersions on the nature of professional development Mathematics teachers in the study receive, but also contrasts sharply with the high quality professional development that research (Archibald et al. 2011) advocates. Since training teachers received was not focused on pedagogical matters such as differentiating instruction and applying appropriate instructional and assessment strategies, teachers would unlikely find the workshops planned for them helpful. From the interviews held with teachers, it emerged that trainers lacked the skills needed for teaching Mathematics to adult learners who, in turn, were expected to teach young learners in the Foundation Phase. This served to weaken rather than enhance the quality of teachers' capacity to teach Mathematics. Again, curriculum advisors' inability to conduct post-training school visits for monitoring and teacher support may be attributed to their lack of confidence rather than the logistical challenges of visiting schools. This does not auger well for improved academic achievement of learners in Mathematics and highlights the need for an intensive training of the trainers.

\section{CONCLUSION}

This study is premised on an empirically established view that poor achievement of South African learners in Mathematics is a function of poor subject knowledge and poor competencies in teaching the subject. Proceeding against the background of inclusive education with its em- 
phasis on catering for the different needs of all learners in education, the study stresses the importance of differentiating curriculum in the teaching of Mathematics, particularly to young learners in lower grades. Such differentiation involves the application of subject-specific differentiation strategies, based on sound differentiation principles that take account of the tested assumption that different learners learn differently and should be taught differently. While literature provides evidence of the benefit of such differentiation in the form of academic achievement of all learners, such benefit cannot be realized in the absence of competent, skilled and professionally developed teachers as this study has found. Considering that teachers are important agents in the process, if they struggle to teach Mathematics effectively, academic achievement in Mathematics will not improve as learners take their share of struggling to learn effectively. The conclusion drawn from this study, therefore, is that a focus needs to be put on well-structured continuing professional development programs for Mathematics teachers and their curriculum advisors, coupled with follow-up monitoring and support processes to ensure that what teachers learn is translated into improved classroom practices. Such development programs should be targeted at improved practice for improved outcomes and factor in the plethora of concerns, misconceptions and challenges teachers have regarding teaching of Mathematics in a differentiated manner.

\section{RECOMMENDATIONS}

In view of the challenges identified in this study, two recommendations are given here. The first recommendation is for schools and their teachers to entrench inclusive practices in the teaching of Mathematics. They need to be creative and develop school-based improvement strategies for the teaching of Mathematics, guided by inclusive education policies. This is possible when Mathematics teachers collectively establish a learning community of practice wherein they learn about new developments in the subject and share problems and best practices. The second recommendation is for the Department of Basic Education in South Africa to take note of the teachers' challenges regarding the teaching of Mathematics in a differentiated manner and address them. To achieve this, it needs to consider shifting its attention from the use of a workshop as the main professional development model for training Mathematics teachers to focusing on job-embedded continuous professional development models, tailored to teachers' needs. This will ensure that training in Mathematics is aligned with practice to improve learner achievement in the subject.

\section{REFERENCES}

AERA 2005. Teaching teachers: Professional development to improve student achievement. Research Points, 3(1): 1-4.

Archibald S, Coggshall JG, Croft A, Goe L 2011. Highquality Professional Development: Effectively Allocating Resources. Washington, DC: National Comprehensive Center for Teacher Quality.

Blozowich DG 2001. Differentiated Instruction in Heterogeneously Grouped Sixth Grade Classrooms. DEd Thesis, Unpublished. Immaculata, PA: Immaculata College.

Borko H 2004. Professional development and teacher learning: Mapping the terrain. Educational Researcher, 33(8): 3-15.

Brunvand S, Byrd S 2011. Using Voice Thread to promote learning engagement and success for all students. Teaching Exceptional Children, 43(4): 20-37.

Darling-Hammond L, Wei RC, Andree A, Richardson $\mathrm{N}$, Orphanos S 2009. Professional Learning in the Learning Profession: A Status Report on Teacher Development in the U.S. and Abroad. Dallas, TX: National Staff Development.

Department of Basic Education 2011a. Guidelines for Responding to Learner Diversity in the Classroom through Curriculum and Assessment Policy Statements. Pretoria: Department of Basic Education.

Department of Basic Education 2011b. Curriculum and Assessment Policy Statement (CAPS): Foundation Phase Mathematics Grade R-3. Pretoria: Department of Basic Education.

Department of Education 2001. Department of Education. Education White Paper 6 on Special Needs Education: Building an Inclusive Education and Training System. Pretoria: Department of Education.

Devetak I, Gla•a SA, Vogrine J 2010. The role of qualitative research in Science Education. Eurasia Journal of Mathematics, Science and Technology, 6(1): 77-84.

Dunne M, Humphreys S, Sebba J, Dyson A, Muijs D 2007. Effective Teaching and Learning for Pupils in Low Attaining Groups. Brighton: University of Sussex.

Easton LB 2008. From professional development to professional learning. Phi Delta Kappan, 89(10): 755-759.

Egbo B 2011. Teacher Capacity Building and Effective Teaching and Learning: A Seamless Connection. A Keynote Speech Delivered at the International Conference on Teaching and Learning Organised by African Association for Teaching and Learning (AATL), held at the Federal College of Education (Technical) Omoku, Rivers State, Nigeria, September 5-8, 2011. 
Ford MP 2005. Differentiation Through Flexible Grouping: Successfully Reaching All Learners. Naperville, IL: Learning Point Associates.

Fullan M 2007. Change the terms for teacher learning. Journal of Staff Development, 28(3): 35-36.

Haywood N, Walker S, Pugh E, Sundaram P 2009. Engaging All Young People in Meaningful Learning After 16: A Review. Manchester: Equality and Human Rights Commission.

INEE 2009. Education in Emergencies: Including Everyone. Geneva: UNHCR.

Kingore B 2007. Reaching All Learners: Making Differentiation Work. Austin, TX: Professional Association Publishing.

Mastropieri MA, Scruggs TE, Norland JJ, Berkely S, McDuffie K, Tornquist EH, Connors N 2006. Differentiated curriculum enhancement in inclusive middle school science: Effects on classroom and high-stakes tests. The Journal of Special Education, 40(3): 130137.

McCarthy J, Oliphant R 2013. Mathematics Outcomes in South African Schools. What are the Facts? What Should be Done? Parktown, Johannesburg: CDE.

Mokua B 2010. An Evaluation of the Curriculum Development Role of Teachers as Key Agents in Curriculum Change. MEd Dissertation. Potchefstroom: North-West University.

Nel M 2007. The Training Needs of South African Inservice Teachers Regarding the Support of Learners Experiencing Barriers to Learning. Paper presented at the AARE Conference, November 2007 at Notre Dame University, Fremantle, Perth, Australia. Paris.

Pierce RL, Adams CM 2004. Tiered lessons: One way to differentiate mathematics instruction. Gifted Child Today, 21(2): 58-66.

Poham WJ 2008. Transformative Assessment. Alexandria, VA: Association of Supervision and Curriculum Development.

Quenemoen R, Thurlow M 2007. Learning Opportunities for Your Child Through Alternative Assessments. Jessup, MD: Ed Pubs, Education Publication Center, U.S. Department of Education. From < www.ed.gov/about/ offices/list/users> (Retrieved on 10 October 2013).

Siyepu S 2013. The zone of proximal development in the learning of mathematics. South African Journal of Education, 33(2): 1-13.
Sparks SD 2015. Differentiated Instruction: A Primer. From <http://www.edweek.org/ew/papers/2015/01/28/ differentiated-instruction-a-primer.html.> (Retrieved on 10 December 2015).

Spaull N 2013. South Africa's Education Crisis: The Quality of Education in South Africa 1994-2011. Parktown, Johannesburg: CDE.

Tate ML 2009. Workshops: Extend learning beyond your presentation with these brain- friendly strategies. Journal of Staff Development, 30(1): 44-46.

Taylor N 2011. National School Effectiveness Study Synthesis Report, 2011. Johannesburg: JET Education Services.

Tomlinson CA 2008. The goals of differentiation. Educational Leadership, 26-30.

Tomlinson CA, Strickland CA 2005. Differentiation in Practice: A Resource Guide for Differentiating Curriculum. Alexandria, VA.: Association for Supervision and Curriculum Development.

UNESCO 2000. The Dakar Framework of Action: Education For all: Meeting Our Collective Commitments. Paris: UNESCO.

UNESCO 2001. Understanding and Responding to Children's' Needs in Inclusive Classrooms. Paris: UNESCO.

UNESCO 2003. Overcoming Exclusion through Inclusive Approaches in Education: A Challenge and a Vision (Conceptual Paper). Paris: UNESCO.

UNESCO 2004. Changing Teaching Practices: Using Curriculum Differentiation to Respond to Students' Diversity. Paris: UNESCO.

UNESCO 2005. Guidelines for Inclusion: Ensuring Access to Education for All. Paris: UNESCO.

UNESCO 2009. Policy Guidelines on Inclusion in Education. Paris: UNESCO.

Vaillant D 2011. Preparing Teachers for Inclusive Education in Latin America. Paris: UNESCO.

Watts J 2010. A Foundational Research Study Connecting Carol A. Tomlinson's Model of Differentiated Instruction to the Study Island Program. Charlottesville, VA: Mongolia Consulting.

Wilkins MM, Wilkins JLM, Oliver T 2006. Differentiating the Curriculum for elementary gifted mathematics Students. Teaching Children Mathematics, 13(1): 1-13. 